\section{BMJ}

Open

Gastroenterology

\title{
Necessity of transnasal gastroscopy in routine diagnostics: a patient-centred requirement analysis
}

\author{
Anna-Livia Schuldt, ${ }^{1}$ Holger Kirsten, ${ }^{2}$ Jan Tuennemann, ${ }^{3}$ Mario Heindl, ${ }^{3}$ \\ Florian van Bommel, ${ }^{4}$ Juergen Feisthammel, ${ }^{1}$ Marcus Hollenbach, ${ }^{1}$ \\ Albrecht Hoffmeister ${ }^{1}$
}

To cite: Schuldt A-L, Kirsten H, Tuennemann J, et al. Necessity of transnasal gastroscopy in routine diagnostics: a patient-centred requirement analysis. BMJ Open Gastro 2019;6:e000264. doi:10.1136/ bmjgast-2018-000264

- Additional material is published online only. To view please visit the journal online (http://dx.doi.org/10.1136/ bmjgast-2018-000264).

Received 6 December 2018 Revised 10 February 2019 Accepted 22 February 2019

Check for updates

(c) Author(s) (or their employer(s)) 2019. Re-use permitted under CC BY-NC. No commercial re-use. See rights and permissions. Published by BMJ.

${ }^{1}$ Division of Gastroenterology, Department of Internal Medicine, Neurology and Dermatology, University of Leipzig, Leipzig, Germany ${ }^{2}$ Institute for Medical Informatics, Statistics and Epidemiology (IMISE), Leipzig, Germany

${ }^{3}$ Division of Gastroenterology, University Hospital Leipzig, Leipzig, Germany

${ }^{4}$ Klinik für Gastroenterologie und Rheumatologie, University Hospital Leipzig, Leipzig, Germany

\section{Correspondence to}

Dr Juergen Feisthammel; juergen.feisthammel@medizin. uni-leipzig.de

\section{ABSTRACT}

Introduction Numerous indications require regular upper gastrointestinal endoscopy

(oesophagogastroduodenoscopy; EGD) in outpatients. In most cases, peroral gastroscopy is performed. The aim of this study was to evaluate the need of transnasal gastroscopy (nEGD) in outpatients.

Methods A questionnaire was used to assess patients' preferred choice of method, previous experience with EGD, psychological aspects and sociodemographic data. Furthermore, patient satisfaction with and potentially perceived discomfort during the examination as well as preference for a method in regard to future examinations was evaluated.

Results From September 2016 to March 2017, a total of 283 outpatients at endoscopy of the University Hospital of Leipzig were approached to participate in the study. 196 patients were eligible, of whom $116(60 \%)$ chose nEGD. For 87 patients $(87 / 283,31 \%)$ nEGD had to be excluded for medical reasons. The average age in the total sample was $53( \pm 17)$ years. $147(77 \%)$ have had previous experience with peroral EGD (0EGD). Of the $\mathrm{nEGD}$ examined patients $83 \%$ were fairly up to extremely satisfied with the procedure. Satisfaction significantly predicted the choice of future EGD examinations. Nasal pain experienced during $\mathrm{nEGDs}$ was associated with rejection of $n E G D$ in further $E G D$ examinations $(p<0.01)$. Patients who did choose a specific procedure were more likely to select the same procedure as their future preference $\left(\chi^{2}=73.6, d f=1, p<0.001\right)$; this preference was unaffected by the procedure that had been chosen previously (reselecting $n E G D: 84 \%, 0 E G D: 89 \%, p=0.874$ ). Conclusion $\mathrm{nEGD}$ without sedation is a viable alternative. Patient satisfaction with $\mathrm{nEGD}$ is high, and reselection rate for $\mathrm{nEGD}$ is similar to that for $\mathrm{OEGD}$. As a result of this study $\mathrm{nEGD}$ is now offered as a routine procedure at the University of Leipzig.

Trial registration number NCT03663491.

\section{INTRODUCTION}

Numerous indications require upper gastrointestinal endoscopy (oesophagogastroduodenoscopy; EGD) regularly. As reviewed by Parker et al, conventional peroral EGD

\section{Summary box}

What is already known about this subject?

- Sedation and therefore sedation-related risks can be avoided by use of $n E G D$. $n E G D$ has the potential to reduce the consumable and pharmaceutical costs.

- In Japan, $\mathrm{nEGD}$ is already performed on a regular basis, whereas in most countries in Europe it has not been implemented on a regular basis.

- So far, high success rates of peroral gastroscopy as well as limited patient tolerance for unsedated gastroscopy are factors indicating the need for the implementation of $n E G D$ in daily routine.

What are the new findings?

- In this prospective clinical trial $84 \%$ of the participants were fairly up to extremely satisfied with the procedure received, independent of the method chosen.

- Nasal pain decreased the odds of reselecting the method by more than $90 \%(\mathrm{OR}=0.098,95 \% \mathrm{Cl} 0.02$ to $0.49, p<0.005$ )

- In this study, the proportion of outpatients who chose the nasal method $(41 \%)$ was significantly different from zero $\left(\chi^{2}=46954.93, \mathrm{df}=1, p<0.001\right.$ with $95 \% \mathrm{Cl} 35 \%$ to $47 \%$ ), which underlines an existing demand for $\mathrm{nEGD}$ in outpatients at the Department of Endoscopy at the University Hospital of Leipzig, Germany.

(oEGD) is used as the standard diagnostic method. ${ }^{1}$ According to the guidelines of the German Society for Gastroenterology, Digestive and Metabolic Diseases, patients have the choice between an examination with or without sedation, using only local anaesthesia, ${ }^{2}$ provided that no contraindications for sedation are known. Peroral gastroscopy under sedation (s-oEGD) increases patients' tolerance towards ${ }^{3}$ and comfort ${ }^{4}$ during the procedure. s-oEGD is also most common in Northern America $^{5}$ and is offered in many European countries as reviewed by Bell et al. ${ }^{6}$ Sedation can increase anaesthesia-related 
Summary box

How might it impact on clinical practice in the foreseeable future?

- Transnasal gastroscopy (nEGD) with ultrathin endoscopes enhances feasibility and patient tolerance in unsedated patients without affecting the quality of the examination. This represents a substantial advance in the field of endoscopy.

- In the present study, the demand for nEGD was evaluated as an alternative to diagnostic upper gastrointestinal endoscopy among outpatients referred to the university hospital. This study showed that patients will choose $\mathrm{nEGD}$ and thereby underlines the existence of a demand for $\mathrm{nEGD}$ in outpatients.

- Guidelines for pretreatment and selection of patients for nEGD will have to be developed in order to facilitate the implementation of $\mathrm{nEGD}$ into the daily routine.

risks, especially in patients presenting with a high American Society of Anesthesiologists score. ${ }^{78}$ Adverse cardiopulmonary events are the most common risk. ${ }^{6-11}$ Sedation requires close monitoring during and after the procedure which increases the procedure's total cost. ${ }^{12-14}$

Unsedated peroral gastroscopy (ns-oEGD) can increase patients' discomfort, which may reduce the overall quality of the examination. ${ }^{1516}$

To further increase patients' comfort during the procedure, the use of ultrathin endoscopes was introduced. In the past, transnasal gastroscopy (nEGD) has been tested as an alternative to oEGD. Shaker reported the feasibility of unsedated nEGD in healthy volunteers in 1994. ${ }^{17}$ In numerous publications, nEGD has been described as a promising alternative, as it reduces cardiac stress level, ${ }^{18}$ shows good patient tolerance, 51416 19-25 leads to less gagging, ${ }^{18} 26$ and, at the same time, is effective and safe. ${ }^{27} 28$ Further studies have shown a high rate of completed procedures as well as reselection of nEGD in patients, who experienced the unsedated method before. ${ }^{162729}$ According to a review on Japanese studies by Tatsumi et al, epistaxis is a main complication in nEGD $(0 \%-5 \%) .^{30}$

On the other hand, nEGD avoids sedation, which minimises the time required for postprocedure observation (cf Ustündag et al). ${ }^{13}$ Also, according to a commentary by Bajaj and Shaker, it keeps the patient from losing a whole day at work ${ }^{31}$ and has the potential to reduce the consumable and pharmaceutical costs by $65 \%-92 \% .^{32}$ Additionally, nEGD is supposed to reduce pharyngeal discomfort and enables the patient to talk during the procedure. ${ }^{182833}$ nEGD is already performed on a regular basis in Asian countries, such as Japan, but in Europe it has been implemented as a regular procedure only in a few countries (eg, France). ${ }^{13}$

The objective of this study was to analyse the necessity and demand for nEGD as an alternative to oEGD in the daily routine in tertiary care and university hospitals.

Furthermore, we aimed to evaluate previous experiences with EGD and its effect on future choices of the patient for a certain examination method. Finally, the study examined the reasons for choosing nEGD or oEGD, evaluated the pain perceived during the procedure and surveyed the resulting preference for choosing a particular method in the future.

\section{MATERIALS AND METHODS}

This prospective clinical study was conducted at the Department of Endoscopy at the University Hospital of Leipzig (UKL), Germany. All outpatients referred to diagnostic EGD at the department during the period from September 2016 until March 2017 were screened for inclusion. Inclusion criteria were: aged $\geq 18$, signed informed consent to participate in this study as well as declaration of consent to undergo the procedure, and an adequate knowledge of oral and written German. Excluded were inpatients receiving EGD as well as all patients unfit to undergo ultrathin nEGD due to medical reasons. Medical reasons for exclusion were a narrow nasal cavity, the potential need to perform band ligation of oesophageal varices, abnormal coagulation profile, the placement of a percutaneous endoscopic gastrostomy, a planned colonoscopy under sedation on the same day or emergency procedures.

From 196 patients who were eligible to undergo nEGD, 194 chose a method. Data collection and evaluation was performed anonymously.

\section{Procedure}

Generally, all outpatients at UKL who will receive EGD are required to attend an informative meeting prior to their examination. Patients fulfilling the inclusion criteria for this study were then handed information explaining nEGD. Potential advantages (avoidance of sedation and the gag reflex as well as a shorter observational period following the procedure) and disadvantages (slightly prolonged procedure, danger of epistaxis and potential need to stop the procedure due to a narrow nasal cavity) were explained on this form. Additionally, the patients were asked to give further information on a questionnaire.

Offered methods were s-oEGD, ns-oEGD as well as unsedated nEGD.

In s-oEGD intravenous anaesthesia was performed with Propofol (Propofol $10 \mathrm{mg} / \mathrm{mL}$ Lipuro, B Braun Melsungen), which was administered under continuous monitoring of blood pressure, blood oxygen saturation, and ECG.

Local anaesthesia was used for patients undergoing ns-oEGD and nEGD. Patients with ns-oEGD received local throat anaesthesia with Xylocaine (Xylocaine $10 \mathrm{mg}$ Spray, AstraZeneca). Patients undergoing nEGD were instructed to nasally inhale Lidocaine jelly (Instillagel 11 mL, Farco-Pharma).

All patients received EGD in the left lateral recumbent position.

Before 6 February 2017, nEGD was performed using solely the FUJIFILM-EG530N-Videoscope (Fujifilm, 
Tokyo, Japan) with an outer diameter of $5.9 \mathrm{~mm}$ and a working channel of $2 \mathrm{~mm}$. After 6 February 2017, the FUJIFILM-EG-580NW2-Videoscope with an outer diameter of $5.9 \mathrm{~mm}$ and a working channel of $2.4 \mathrm{~mm}$ was used as well. ns-oEGD and s-oEGD were performed using the FUJIFILM-EG590WR-Video and FUJIFILM-EG530WR-Video endoscopes with an outer diameter of 9.3 $\mathrm{mm}$ and a working channel of $2.8 \mathrm{~mm}$. All endoscopes had a length of $1100 \mathrm{~mm}$.

A routine examination consisted of examining the upper gastrointestinal tract up to the descending part of the duodenum. Biopsy samplings were performed when needed.

Criteria for discontinuation of nEGD were impossible passage through the nasal cavity after trying both nostrils separately and severe epistaxis.

The endoscopies were performed by trained and experienced endoscopists.

\section{Patients' questionnaire}

The questionnaire included on the first page information with descriptive imaging. This ensured standardised explanation of the procedure to minimise physicians' influence on the patients' decision-making for one or the other method.

The questionnaire itself consisted of two parts (online supplementary file 1). Part 1: Prior to the procedure the patients were asked to give information on their previous experience with EGD, their concerns regarding the actual examination, sociodemographic data, their choice of examination method (nEGD, ns-oEGD, s-oEGD) as well as their reasons for it.

The second part was completed after the procedure, evaluating the discomfort experienced during the examination specifically during the procedure of intubation of the nose, discomfort felt in the throat or stomach, and severity of pain during the procedure. The discomfort was measured with the numeric analogue scale (NAS) (NAS 0: no discomfort; 10: pain could not be worse). Patients were also asked to state their future preference for following procedures and the reasons for their preference. Only patients who had chosen ns-oEGD or nEGD were asked to answer the second part of the questionnaire.

\section{Physicians' questionnaire}

A questionnaire was handed out to the physicians performing the endoscopy exploring the endoscopic experience of the physician in general and with nEGD, their preference for a certain method, and if they wish to include nEGD in routine diagnostics (online supplementary file 2 ).

\section{Statistical analyses}

For the statistical analysis, PASW statistics (SPSS. Released 2009. PASW Statistics for Windows. V.18.0. Chicago: SPSS) and R Core Team (2014) (R: A language and environment for statistical computing. $\mathrm{R}$ Foundation for Statistical Computing, Vienna, Austria. URL http:/ /
www.R-project.org/) were used. Descriptive statistics were used to determine the percentage of patients who chose nEGD, ns-oEGD or s-oEGD. Means were calculated and group variability was reported as the SD. Categorical data were compared by using Fisher's exact test or $\chi^{2}$ test. Data with a normal distribution were compared with a Student's t-test. Binary logistic regression was used to assess the effect of predictors for the repeated selection of nEGD. The dependent variable was repeated selection of the respective method $(1=y e s, 0=$ no). Independent variables in the model were satisfaction (1=moderate, fairly, and extremely; $0=$ little, not at all) and perceived nasal pain $(1=y e s ; 0=$ no). Differences were considered statistically significant when $\mathrm{p}<0.05$. $\mathrm{R}$ function prop.test was used for testing the null that the proportions of individuals who reselected the same method for future examination is 0.5 . Our sample size of 196 patients powers our analysis to estimate the proportion of patients who select a certain method with a two-sided $95 \%$ CI width equal to $11.7 \%, 13.2 \%$, and $14.4 \%$ when the sample proportion would be $20 \%, 30 \%$, and $50 \%$, respectively.

This study was registered at ClinicalTrials.gov with the ID NCT03663491.

\section{RESULTS}

\section{Response rate}

During the study period a total of 2523 patients underwent EGD at UKL. Of this total number, 843 were enrolled as outpatients and were therefore potential candidates for this study. Of these, 283 (34\%) agreed to participate in the study. Loss of candidates can be attributed to emergency examinations or patients who were referred to the department by special outpatient clinics that did not have access to the questionnaire needed for the study (figure 1; tables 1 and 2).

\section{General characteristics of the sample}

The group of participants medically eligible for nEGD consisted of 83 males (43\%) and 110 females (57\%), with an average age of $53( \pm 17)$ years $($ table 3$)$.

Seventy-seven per cent $(147 / 191)$ of the participants stated previous experience with EGD. Indications for EGD were general monitoring of Barrett's epithelium, oesophageal varices, ulcus, and so on $(75 / 175,43 \%)$, complaints and symptoms $(79 / 175,45 \%)$, and preinterventional examination before surgery or endoscopic suturing $(21 / 175,12 \%)$. There was no significant correlation between the indication for the examination and the examination method chosen (Fisher's exact test, $\mathrm{p}=0.347$ ).

Table 4 shows the sociodemographic data of the patients participating in the study. In contrast to age, the proportion of male and female patients differed significantly between the three groups (Fisher's exact test, $\mathrm{p}=0.013$ ). No significant correlation between educational status ( $\mathrm{p}=0.242)$, marital status $(\mathrm{p}=0.386)$ or body mass index $(p=0.534)$ and the choice of a certain method could be 


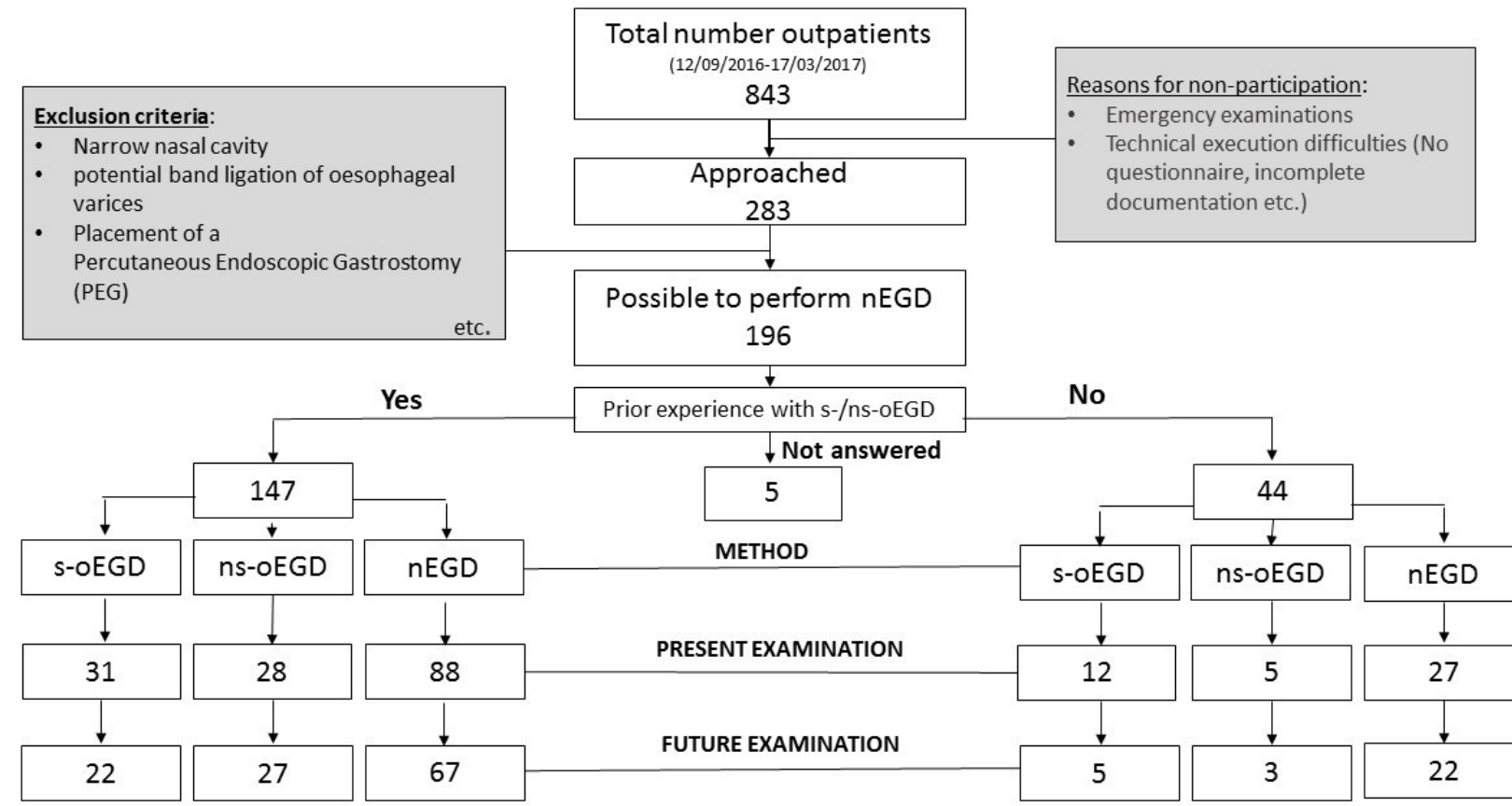

Flow chart: patient recruitment, exclusion criteria, reasons for non-participation, prior experience and chosen method as well as preference of a method for potential future examinations; 5 not answered (2 $s$-oEGD, 1 nEGD, 2 missings)

Abbreviations: s-oEGD: sedated peroral gastroscopy, ns-oEGD: unsedated peroral gastroscopy, $n E G D$ : unsedated transnasal gastroscopy

Figure 1 Flow chart. nEGD, transnasal gastroscopy; ns-oEGD, unsedated peroral gastroscopy; s-oEGD, peroral gastroscopy under sedation.

shown. In all groups, the number of patients who stated previous experience with oEGD was higher than the number of those with no prior experience $(147 / 44)$.

The insertion failure rate for $\mathrm{nEGD}$ was $10 \%$, all due to narrow nasal cavities. In these cases, the examination was then successfully finished with the ultrathin video endoscopes via the peroral route.

\section{Perception of the chosen method}

Eighty-four per cent of the participants were fairly up to extremely satisfied with their procedure, independent of the method chosen (table 5). Throughout the groups, a significant correlation between the degree of satisfaction

Table 1 Overview of outpatients, University Clinic Leipzig, Gastroscopy (12 September 2016 to 17 March 2017)

\begin{tabular}{|c|c|}
\hline Total number of patients & 2523 \\
\hline Outpatients & $843(33 \%)$ \\
\hline Inpatients & $1680(67 \%)$ \\
\hline Outpatients & $843(100 \%)$ \\
\hline Intravenous sedation & $327(39 \%)$ \\
\hline Local anaesthesia & $429(51 \%)$ \\
\hline Oral & $313 / 843(37 \%)$ \\
\hline Nasal & $116 / 843(14 \%)$ \\
\hline Without data* & $83(10 \%)$ \\
\hline Total number outpatients approached & $283 / 843(34 \%)$ \\
\hline
\end{tabular}

*No reported choice for an examination method in the clinical records at the Department for Endoscopy at University Hospital Leipzig, Germany. and the re-election of the same procedure in future examination could be identified (Fisher's exact test, $\mathrm{p}=0.007$ ) .

In the nEGD group, satisfaction with the endoscopy also correlated significantly with the re-election of the same method for future examination (Fisher's exact test, $\mathrm{p}=0.002$ ). Due to the similarity of the OR (the ns-oEGD group [ $4.7,95 \%$ CI 0.06 to 142.5 ] and the nEGD group [5.5, 95\% CI 1.3 to 22.8]), the rate of satisfaction was not significantly different in the two groups (Fisher's exact test, nEGD: $\mathrm{p}=0.002$; ns-oEGD: $\mathrm{p}=0.169$ ).

The amount of perceived nasal pain (average 4.24 [ \pm 2.36$])$ had a significant impact on re-election of nEGD

Table 2 Number of patients approached and response rate categorised by the clinical feasibility of the transnasal approach

\begin{tabular}{lll}
\hline Number of patients approached & $\begin{array}{l}\text { nEGD } \\
\text { possible }\end{array}$ & $\begin{array}{l}\text { nEGD not } \\
\text { possible* }\end{array}$ \\
\hline $\mathbf{n = 2 8 3 ~ ( 1 0 0 \% ) ~}$ & $\mathbf{1 9 6}(\mathbf{6 9 \% )})$ & $\mathbf{8 7}(\mathbf{3 1} \%)$ \\
\hline Method chosen & & \\
$\quad$ Oral gastroscopy with & $45 / 194$ & \\
intravenous sedation (s-oEGD) & $(23 \%)$ & \\
Oral gastroscopy with local & $33 / 194$ \\
anaesthesia (ns-oEGD) & $(17 \%)$ \\
Nasal gastroscopy (nEGD) & $116 / 194$ \\
& $(60 \%)$ & \\
&
\end{tabular}

*Exclusion criteria: narrow nasal cavity, potential need to perform band ligation of oesophageal varices, placement of a percutaneous endoscopic gastrostomy (PEG), emergency procedures. 
Table 3 Sociodemographic characteristics of the study population

Total sample, $\mathrm{n}=196(100 \%)$

\begin{tabular}{ll} 
Age (mean \pm SD) & $53( \pm 17)$ \\
Gender & \\
\hline Male & $83 / 193(43 \%)$ \\
\hline Female & $110 / 193(57 \%)$ \\
\hline Educational status & \\
\hline Mandatory school & $39 / 174(22 \%)$ \\
\hline High school & $81 / 174(47 \%)$ \\
\hline University degree & $54 / 174(31 \%)$ \\
\hline Reason for examination & \\
\hline Monitoring & $75 / 175(43 \%)$ \\
\hline Symptoms & $79 / 175(45 \%)$ \\
\hline Preoperative & $21 / 175(12 \%)$ \\
\hline Previous experience with oral & \\
gastroscopy & \\
\hline Yes & $147 / 191(77 \%)$ \\
\hline None & $44 / 191(23 \%)$ \\
\hline BMl (kg/m²) & \\
\hline Underweight & $9 / 189(5 \%)$ \\
\hline Healthy weight & $74 / 189(39 \%)$ \\
\hline Overweight & $42 / 189(22 \%)$ \\
\hline Obesity & $64 / 189(34 \%)$ \\
\hline Bil & \\
\hline
\end{tabular}

${ }^{*}$ BMI $\left(\mathrm{kg} / \mathrm{m}^{2}\right)$ : Age $<34$ years: underweight $\left(<19 \mathrm{~kg} / \mathrm{m}^{2}\right)$, healthy weight $\left(19-24 \mathrm{~kg} / \mathrm{m}^{2}\right)$, overweight $\left(25-30 \mathrm{~kg} / \mathrm{m}^{2}\right)$, obesity $(>30$ $\left.\mathrm{kg} / \mathrm{m}^{2}\right)$. Age $\geq 34$ years: underweight $\left(<19 \mathrm{~kg} / \mathrm{m}^{2}\right)$, healthy weight $\left(19-26 \mathrm{~kg} / \mathrm{m}^{2}\right)$, overweight $\left(27-30 \mathrm{~kg} / \mathrm{m}^{2}\right)$, obesity $\left(>30 \mathrm{~kg} / \mathrm{m}^{2}\right)$ (Deutsche Gesellschaft für Ernährung, The German Nutrition Society [DGE]).

BMI, body mass index.

as the preferred method $(\mathrm{p}=0.001)$. Sex $(\mathrm{p}=0.59)$, throat pain $(\mathrm{p}=1.000)$, gag reflex $(\mathrm{p}=0.592)$ and abdominal pain $(p=1.000)$ did not have a significant impact on the method re-elected.

Sex $(p=0.25)$, throat pain perceived during the examination $(p=1.000)$, the gag reflex $(p=0.530)$, and abdominal pain $(p=1.000)$ could not be identified as factors with significant impact on repeated selection in the ns-oEGD group.

To examine whether repeated selection was based on satisfaction or perceived nasal pain, a binary logistic regression was used to model the effect of these two factors in the 116 patients who had chosen nEGD. The full regression model (likelihood ratio test against intercept-only model: $\chi^{2}=18154, \mathrm{df}=2, \mathrm{p}<0.001, \mathrm{n}=99$ ) as well as both variables can be considered significantly associated in repeated selection of the same method. The ORs of re-electing the same method were more than five times higher in satisfied patients in comparison to unsatisfied patients $(\mathrm{OR}=5.4,95 \%$ CI 1.4 to 21.5, $\mathrm{p}=0.02)$. Nasal pain, however, decreased the odds of re-election of the same method by more than $90 \% \quad(\mathrm{OR}=0.098,95 \%$ CI
Table 4 Examined study group categorised by type of examination method

\begin{tabular}{|c|c|c|c|c|}
\hline Method & S-OEGD & ns-oEGD & nEGD & $P$ value \\
\hline $\begin{array}{l}\text { Age } \\
(\text { mean } \pm S D)\end{array}$ & $48( \pm 16)$ & $56( \pm 18)$ & $53( \pm 16)$ & $\begin{array}{l}\text { Not } \\
\text { significant }\end{array}$ \\
\hline \multicolumn{5}{|l|}{ Gender } \\
\hline Male & $\begin{array}{l}12 / 45 \\
(27 \%)\end{array}$ & $\begin{array}{l}12 / 33 \\
(36 \%)\end{array}$ & $\begin{array}{l}59 / 115 \\
(51 \%)\end{array}$ & 0.013 \\
\hline Female & $\begin{array}{l}33 / 45 \\
(73 \%)\end{array}$ & $\begin{array}{l}21 / 33 \\
(64 \%)\end{array}$ & $\begin{array}{l}56 / 115 \\
(49 \%)\end{array}$ & \\
\hline \multicolumn{5}{|l|}{$\begin{array}{l}\text { Educational } \\
\text { status }\end{array}$} \\
\hline $\begin{array}{l}\text { Mandatory } \\
\text { school }\end{array}$ & $\begin{array}{l}13 / 44 \\
(30 \%)\end{array}$ & $\begin{array}{l}8 / 28 \\
(29 \%)\end{array}$ & $\begin{array}{l}18 / 105 \\
(17 \%)\end{array}$ & $\begin{array}{l}\text { Not } \\
\text { significant }\end{array}$ \\
\hline High school & $\begin{array}{l}22 / 44 \\
(50 \%)\end{array}$ & $\begin{array}{l}11 / 28 \\
(39 \%)\end{array}$ & $\begin{array}{l}51 / 105 \\
(49 \%)\end{array}$ & \\
\hline $\begin{array}{l}\text { University } \\
\text { degree }\end{array}$ & $\begin{array}{l}9 / 44 \\
(20 \%)\end{array}$ & $\begin{array}{l}9 / 28 \\
(32 \%)\end{array}$ & $\begin{array}{l}36 / 105 \\
(34 \%)\end{array}$ & \\
\hline \multicolumn{5}{|l|}{$\mathrm{BMI}\left(\mathrm{kg} / \mathrm{m}^{2}\right)^{*}$} \\
\hline Underweight & $\begin{array}{l}2 / 44 \\
(5 \%)\end{array}$ & $2 / 33(6 \%)$ & $\begin{array}{l}5 / 112 \\
(4 \%)\end{array}$ & \\
\hline $\begin{array}{l}\text { Healthy } \\
\text { weight }\end{array}$ & $\begin{array}{l}22 / 44 \\
(50 \%)\end{array}$ & $\begin{array}{l}14 / 33 \\
(42 \%)\end{array}$ & $\begin{array}{l}38 / 112 \\
(34 \%)\end{array}$ & $\begin{array}{l}\text { Not } \\
\text { significant }\end{array}$ \\
\hline Overweight & $\begin{array}{l}9 / 44 \\
(20 \%)\end{array}$ & $\begin{array}{l}5 / 33 \\
(15 \%)\end{array}$ & $\begin{array}{l}28 / 112 \\
(25 \%)\end{array}$ & \\
\hline Obesity & $\begin{array}{l}11 / 44 \\
(25 \%)\end{array}$ & $\begin{array}{l}12 / 33 \\
(37 \%)\end{array}$ & $\begin{array}{l}41 / 112 \\
(37 \%\end{array}$ & \\
\hline
\end{tabular}

Previous

experience

with oral

gastroscopy

\begin{tabular}{lllll} 
Yes & $31 / 43$ & $28 / 33$ & $88 / 115$ & Not \\
& $(72 \%)$ & $(85 \%)$ & $(77 \%)$ & significant \\
None & $12 / 43$ & $5 / 33$ & $27 / 115$ & \\
& $(28 \%)$ & $(15 \%)$ & $(23 \%)$ & \\
\hline
\end{tabular}

${ }^{*}$ BMI $\left(\mathrm{kg} / \mathrm{m}^{2}\right)$ : Age $<34$ years: underweight $\left(<19 \mathrm{~kg} / \mathrm{m}^{2}\right)$, healthy weight $\left(19-24 \mathrm{~kg} / \mathrm{m}^{2}\right)$, overweight $\left(25-30 \mathrm{~kg} / \mathrm{m}^{2}\right)$, obesity $(>30$ $\left.\mathrm{kg} / \mathrm{m}^{2}\right)$. Age $\geq 34$ years: underweight $\left(<19 \mathrm{~kg} / \mathrm{m}^{2}\right)$, healthy weight $\left(19-26 \mathrm{~kg} / \mathrm{m}^{2}\right)$, overweight $\left(27-30 \mathrm{~kg} / \mathrm{m}^{2}\right)$, obesity $\left(>30 \mathrm{~kg} / \mathrm{m}^{2}\right)$ (Deutsche Gesellschaft für Ernährung, The German Nutrition Society [DGE]).

BMI, body mass index; nEGD, transnasal gastroscopy; ns-oEGD, unsedated peroral gastroscopy; s-oEGD, peroral gastroscopy under sedation.

0.02 to $0.49, \mathrm{p}<0.005)$. The Nagelkerke pseudo- $\mathrm{R}^{2}$ of the model was 0.301 , this corresponds with a strong impact according to Cohen. ${ }^{34}$

The proportion of outpatients with prior experience in oral gastroscopy who chose the nasal method and who would re-elect the nasal method for future examination was $84 \%$ ( $\mathrm{p}=0.001$ with $95 \%$ CI $73 \%$ to $91 \%$ ).

There was also no significant difference between re-election rates within the three different methods ( $\mathrm{p}=0.874$, s-oEGD 16/18 [89\%]; ns-oEGD 24/27 [89\%]; nEGD 86/102 [84\%]) (tables 6-8). 


\begin{tabular}{llll}
\hline \multicolumn{3}{l}{ Table 5} & \multicolumn{3}{c}{ Satisfaction rate characterised by chosen method } \\
\hline $\mathbf{n E G D}(\mathbf{n}=\mathbf{1 0 2})$ & \multicolumn{3}{c}{$\mathbf{n s - o E G D}(\mathbf{n}=\mathbf{2 7})$} \\
\hline Total sample & $102(100 \%)$ & Total sample & $27(100 \%)$ \\
\hline Not at all & $4 / 102(4 \%)$ & Not at all & $0 / 27$ \\
\hline Little & $2 / 102(2 \%)$ & Little & $0 / 27$ \\
Moderate & $11 / 102(11 \%)$ & Moderate & $3 / 27(11 \%)$ \\
Fairly & $37 / 102(36 \%)$ & Fairly & $5 / 27(19 \%)$ \\
Extremely & $48 / 102(47 \%)$ & Extremely & $19 / 27(70 \%)$ \\
\hline
\end{tabular}

No significant difference in the rate of satisfaction $(p=0.169)$. $\mathrm{nEGD}$, transnasal gastroscopy; ns-oEGD, unsedated peroral gastroscopy.

Overall patient's re-election rate was $86 \%(126 / 147)$ which was significantly different from random choice $\left(\chi^{2}=73.6, \mathrm{df}=1, \mathrm{p}<0.001\right)$. This rate was similar among participants with prior EGD experience $(101 / 116,87 \%$, $\chi^{2}=62.3, \mathrm{df}=1, \mathrm{p}<0.001$ ) (figure 2).

T-test showed no significant age difference $(\mathrm{t}=0259$, $\mathrm{df}=125, \mathrm{p}=0.796)$ nor Fisher's exact test a significant difference for sex (nEGD: $p=0.59$; ns-oEGD: $p=0.25$ ) in the groups that re-elected the same method for future proceedings.

The transnasal approach was chosen by $41 \%$ of patients included in this study $\left(\chi^{2}=46954.93, \mathrm{df}=1, \mathrm{p}<0.001\right.$ with $95 \%$ CI $35 \%$ to $47 \%)$.

\section{Physicians' responses concerning nEGD}

Ten physicians performed the endoscopies at the Department of Endoscopy at the UKL and answered the distributed questionnaire. Previous experience with standard endoscopic procedure was on average 7.6 years $( \pm 4.79)$. Six out of these 10 physicians expressed a desire to offer nEGD in daily practice. Reasoning was the avoidance of anaesthesia as well as faster mobilisation of the patients after completion of the examination. Two out of 10 stated nEGD as their preferred method of EGD, whereas six preferred ns-oEGD and two s-oEGD.

\section{DISCUSSION}

EGD is frequently used as a diagnostic tool to detect gastrointestinal pathology. To reduce patients' discomfort and anxiety as well as to avoid sedation-related adverse effects, nEGD with ultrathin endoscopes has been considered

\begin{tabular}{|c|c|c|}
\hline Chosen method & ns-oEGD & nEGD \\
\hline \multicolumn{3}{|c|}{$\begin{array}{l}\text { Repeated selection } \\
\text { for future examination }\end{array}$} \\
\hline Yes & $24 / 27$ (89\%) & $86 / 102(84 \%)$ \\
\hline No & 3/27 (11\%) & 16/102 (16\%) \\
\hline
\end{tabular}

nEGD, transnasal gastroscopy; ns-oEGD, unsedated peroral gastroscopy.
Table 7 Study group: selected method, repeated selection and previous experience of oral gastroscopy

\begin{tabular}{|c|c|c|c|c|}
\hline Experience & Yes & & No & \\
\hline & ns-oEGD & nEGD & ns-oEGD & nEGD \\
\hline Chosen method & 28 & 88 & 5 & 27 \\
\hline \multicolumn{5}{|l|}{$\begin{array}{l}\text { Repeated } \\
\text { selection for future } \\
\text { examination }\end{array}$} \\
\hline Yes & $\begin{array}{l}22 / 28 \\
(79 \%)\end{array}$ & $\begin{array}{l}66 / 88 \\
(75 \%)\end{array}$ & $2 / 5(40 \%)$ & $\begin{array}{l}20 / 27 \\
(74 \%)\end{array}$ \\
\hline No & $2 / 28(7 \%)$ & $\begin{array}{l}13 / 88 \\
(15 \%)\end{array}$ & $1 / 5(20 \%)$ & $\begin{array}{l}3 / 27 \\
(11 \%)\end{array}$ \\
\hline Incomplete data & $\begin{array}{l}4 / 28 \\
(14 \%)\end{array}$ & $\begin{array}{l}9 / 88 \\
(10 \%)\end{array}$ & $2 / 5(40 \%)$ & $\begin{array}{l}4 / 27 \\
(15 \%)\end{array}$ \\
\hline
\end{tabular}

nEGD, transnasal gastroscopy; ns-oEGD, unsedated peroral gastroscopy.

a major advance in the field, enhancing feasibility and patient tolerance without affecting the quality of the examination. ${ }^{19}$ A study conducted by Dumortier et al in France, including 1100 consecutive patients, in three different institutions, proved the feasibility of nEGD with ultrathin video endoscopes and showed patients' preference for this technique. ${ }^{35}$ Further studies found nEGD to be safe, effective, and better tolerated by the patients. ${ }^{27}$

In the present study, we focused on the evaluation of a demand for nEGD as an alternative option for diagnostic EGD among outpatients referred to the UKL. In the group of outpatients who did not show medical conditions contradicting nEGD, $60 \%$ chose nEGD. This high proportion underlines an existing demand for nEGD in outpatients.

As reviewed by Tatsumi et al, nEGD is used increasingly for endoscopic procedures in Japan, ${ }^{30}$ which poses the question why nEGD has not been implemented more frequently in other countries, for example, Germany.

One reason might be that up until now not many patients have undergone this procedure which makes a substantiated statement about the actual complication rates difficult as reviewed by Tatsumi $e t a l .{ }^{30}$ Other reasons may be a lack of randomised prospective studies and cost-effectiveness analysis (cf Ustündag et al) ${ }^{13}$ Further

Table 8 Selected method and choice for future examination in the total sample group, $n=147$

\begin{tabular}{llll}
\hline $\begin{array}{l}\text { Chosen } \\
\text { method }\end{array}$ & $\begin{array}{l}\text { s-oEGD } \\
(\mathbf{n = 1 8})\end{array}$ & $\begin{array}{l}\text { ns-oEGD } \\
(\mathbf{n = 2 7})\end{array}$ & nEGD (n=102) \\
\hline $\begin{array}{l}\text { Future } \\
\text { examination }\end{array}$ & & & \\
\hline s-oEGD & $16 / 18(89 \%)$ & $1 / 27(4 \%)$ & $10 / 102(10 \%)$ \\
ns-oEGD & $1 / 18(5.5 \%)$ & $24 / 27(89 \%)$ & $6 / 102(6 \%)$ \\
nEGD & $1 / 18(5.5 \%)$ & $2 / 27(7 \%)$ & $86 / 102(84 \%)$ \\
\hline
\end{tabular}

Reselection rate $86 \%(p<0.001)$.

nEGD, transnasal gastroscopy; ns-oEGD, unsedated peroral gastroscopy; s-oEGD, peroral gastroscopy under sedation. 


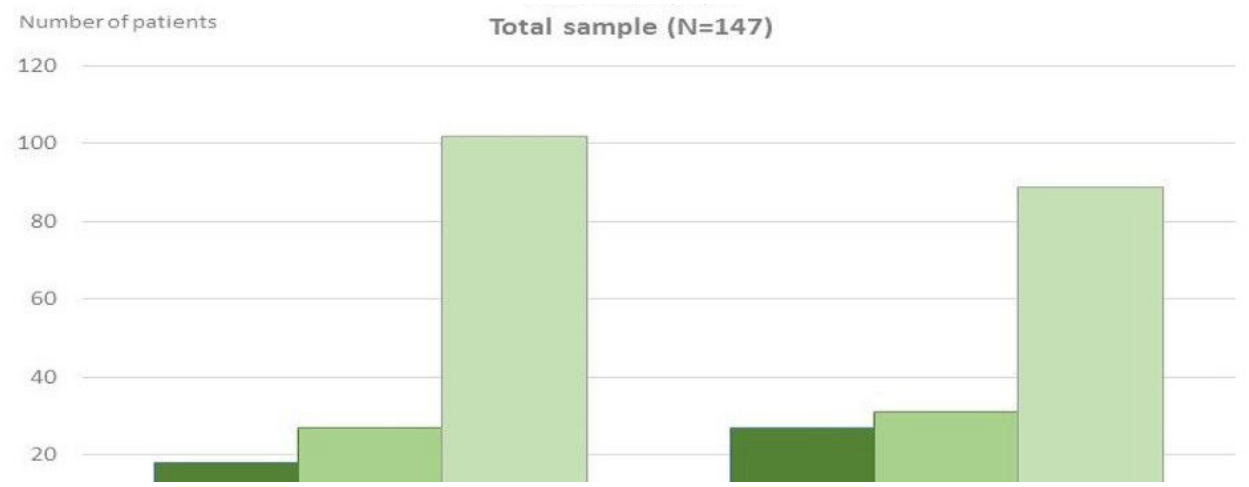

Figure 2 Chosen method and preferred method for future examination.

arguments questioning the need for the implementation of nEGD in daily practice are: the high success rate of oEGD, ${ }^{36}$ a similar tolerance for oEGD compared with nEGD,${ }^{37}$ limited patient tolerance for unsedated gastroscopy, and a higher acceptability to undergo oEGD again if necessary, compared with nEGD ${ }^{38}$ In our study, nEGD failed in $10 \%$ of the examinations. oEGD was successfully performed with the ultrathin endoscope in all cases. Patients, who had chosen nEGD or ns-oEGD, were more likely to report the same procedure as their preference for future examinations; regardless of the method they were examined with. This indicates a similar tolerance towards both techniques. A preference for oEGD in general was not detected.

Neuenschwander et al stated nEGD as technically inferior to oEGD and that no benefit for overall comfort could have been found in the study including 98 patients (nEGD: 48; oEGD: 50). He stated though that the reduced stress levels during nEGD and its clinical relevance would have to be further investigated. ${ }^{18}$ Furthermore, oEGD was found to be preferred by both physicians and patients in one study from 1999, using a $5.3 \mathrm{~mm}$ fibre-optic endoscope and a $5.9 \mathrm{~mm}$ video endoscope. ${ }^{37}$ In 1999, ultrathin video endoscopes had not yet been implemented on a regular basis in endoscopic practice. When asked, 2 out of 10 practising physicians in our unit stated nEGD as their preferred method for diagnostic EGD, whereas six preferred ns-oEGD and two s-oEGD.

This may be explained by the lack of experience and training with nEGD as a daily routine causing doubts about advantages and qualities of nEGD. ${ }^{29}{ }^{39}$ Additionally, the expenses of buying the new technology might influence the implementation progress. The development of a dedicated nEGD training has been suggested to increase physicians' familiarity with the procedure (cf Parker $e t a l) .{ }^{1}$ A survey by Atar and Kadayifcienhanced the request for the inclusion of nEGD training in gastroenterology fellowships, as this method could reduce costs while maintaining the quality and increasing the patients' overall comfort, only nasal pain being a significant symptom during the examination. ${ }^{40}$ Except for perceived nasal pain, nEGD was found to be better tolerated by EGD experienced patients in a randomised study by Kadayifci $e t a l .{ }^{16}$ This overlaps with the findings of our present study, where, besides satisfaction, only perceived nasal pain had a significant impact on further patient choices for nEGD as the method for future examination. This could be moderated by sufficient nasal anaesthesia, which was found to be vital to reducing nasal pain during insertion. ${ }^{36}$

Concerns about the adequacy of biopsy samples taken with small forceps can be obliterated by studies that were able to prove the adequacy of small biopsy samples. ${ }^{25} 374142$ However, the overall adequacy of the biopsies will have to be further investigated in bigger studies. As limitations of the ultrathin endoscopes (which are used in nEGD) do not compromise diagnostic EGD, nEGD shows to be a great alternative for patients, in whom oEGD cannot be performed due to anatomical reasons. ${ }^{43}$ Further studies testing the appropriateness of nEGD for interventional purposes need to be conducted. In the placement of feeding tubes, nEGD has shown to be an adequate alternative reducing procedure time and medication required, ${ }^{44}$ even feasible in patients who are critically ill. ${ }^{45}$ Success rates were found to be highly impacted by practice skills of the physicians. ${ }^{45}$

Epistaxis was, with 5\%, found to be the most common complication during nEGD as reported in Japanese studies ${ }^{30}$ which generally stops spontaneously. ${ }^{37}$ Other risks related to sedation, such as cardiopulmonary problems that might comprise up to $50 \%$ of complications and $60 \%$ of endoscopy-related deaths, according to Bell et $a l$ s review, ${ }^{6}$ can be avoided by nEGD practice. Additionally, Ooi and Thomson described endoscopist-directed nurse-administered propofol sedation as inappropriate for high-risk patients. ${ }^{8}$ Following a prospective randomised comparative study, Yuki et al stated transnasal small-calibre endoscopy to even be a safer method compared with transoral conventional endoscopy in patients who are critical ill. ${ }^{46}$

Our study showed a demand for the offer of nEGD among outpatients. The overall satisfaction rate was high and $84 \%$ of the patients who had chosen nEGD were willing to undergo the same procedure in future examinations. Differing from previous studies, ${ }^{35}$ no impact of age or sex on the decision for or re-election of a method was identified. This study is a single-centre study. 
One limitation of the study is that potential outpatient candidates were missed due to organisational difficulties as well as difficulties in cooperation with specialised outpatient clinics that did not have access to the studies' questionnaire. Personal doubts among the physicians about the quality of the examination and, therefore, varying information given during the informative meeting may have had an impact on the total number of patients who did choose nEGD. The availability of the transnasal gastroscope with a working channel of $2.4 \mathrm{~mm}$ in our department from February 2017 onwards was an advantage as a previous retrospective study showed that this working channel size reduces suction and therefore overall procedure time significantly. ${ }^{47}$ To further validate our findings of a potential demand for nEGD in the daily routine, larger studies will be needed, addressing the demand and the efficacy of pretreatment and increasing abilities of the responsible physician.

Following this study, at the Department of Endoscopy at the University Hospital Leipzig, Germany, nEGD is offered as an alternative for diagnostic endoscopy of the upper gastrointestinal tract in daily routine.

In conclusion, nEGD has proven to be a safe and well-tolerated alternative to oEGD. It has the potential to reduce sedation-related risks, reduce cost and enable EGD in patients not suitable for oEGD. nEGD therefore represents a substantial advance in the field of diagnostic endoscopy when being implemented in Germany. Regarding interventional EGD further studies will have to be conducted in order to be able to substantially make a statement about the amount of possible complications. Guidelines for pretreatment and the selection of patients for nEGD will have to be developed to facilitate the implementation of nEGD in daily routine.

Contributors ALS planned the study and participated in the implementation, evaluation and submission of the study. HK participated in the planning and evaluation of the study. JT, MH, FvB and MH all conducted the examinations. JF conducted the examinations as well as submitted the article. AH is the guarantor of the study and supervised the entire study planning, implementation and submission of the study.

Funding The authors have not declared a specific grant for this research from any funding agency in the public, commercial or not-for-profit sectors.

Competing interests None declared.

Patient consent for publication Not required.

Ethics approval The Ethical Committee of the Medical Faculty of Leipzig University approved the study (registration number 328/16-ek).

Provenance and peer review Not commissioned; externally peer reviewed.

Data sharing statement All individual participant data that underlie the results in this article are included in the article after deidentification (text, tables, figures and appendices). Any additional data may be provided on demand to researchers who provide a methodologically sound proposal in order to achieve aims in the approved proposal. To gain access, data requestors will need to sign a data access agreement.

Open access This is an open access article distributed in accordance with the Creative Commons Attribution Non Commercial (CC BY-NC 4.0) license, which permits others to distribute, remix, adapt, build upon this work non-commercially, and license their derivative works on different terms, provided the original work is properly cited, appropriate credit is given, any changes made indicated, and the use is non-commercial. See: http://creativecommons.org/licenses/by-nc/4.0/.

\section{REFERENCES}

1. Parker C, Alexandridis E, Plevris J, et al. Transnasal endoscopy: no gagging no panic! Frontline Gastroenterol 2016;7:246-56.

2. Riphaus A, Wehrmann T, Hausmann J, et al. A. S3-Leitlinie Sedierung in Der gastrointestinalen Endoskopie 2014 (AWMFRegister-Nr. 021/ 014). Z Gastroenterol 2015;53:802-42.

3. Froehlich F, Schwizer W, Thorens J, et al. Conscious sedation for gastroscopy: patient tolerance and cardiorespiratory parameters. Gastroenterology 1995;108:697-704.

4. Behrens A, Ell C. Sicherheit Der Sedierung Der Gastroskopie und Koloskopie bei Niedrigrisikopatienten - Retrospektive Subgruppenanalyse Der Ergebnisse einer Registerstudie von über 170000 Endoskopien. Z Gastroenterol 2016;54:733-9.

5. Cho S, Arya N, Swan K, et al. Unsedated transnasal endoscopy: a Canadian experience in daily practice. Can $\mathrm{J}$ Gastroenterol 2008;22:243-6.

6. Bell GD. Premedication, preparation, and surveillance. Endoscopy 2002;34:2-12.

7. American Society of Anesthesiologists. American Society of Anesthesiologists - ASA Physical Status Classification System, 2014. Available: https://www.asahq.org/resources/clinicalinformation/asa-physical-status-classification-system [Accessed 31 Mar 2017].

8. Ooi M, Thomson A. Morbidity and mortality of endoscopist-directed nurse-administered propofol sedation (EDNAPS) in a tertiary referral center. Endosc Int Open 2015;3:E393-E397.

9. Aviv JE. Transnasal esophagoscopy: state of the art. Otolaryngol Head Neck Surg 2006;135:616-9.

10. Levy I, Gralnek IM. Complications of diagnostic colonoscopy, upper endoscopy, and enteroscopy. Best Pract Res Clin Gastroenterol 2016;30:705-18.

11. Hart R, Classen M. Complications of diagnostic gastrointestinal endoscopy. Endoscopy 1990;22:229-33.

12. Garcia RT, Cello JP, Nguyen MH, et al. Unsedated ultrathin EGD is well accepted when compared with conventional sedated EGD: a multicenter randomized trial. Gastroenterology 2003;125:1606-12.

13. Ustündağ $Y$, Saritaș U, Ponchon T. Unsedated small caliber esophagogastroduodenoscopy: can we trust this technique? Turk J Gastroenterol 2011;22:237-42.

14. Luman W. Patients' perception of transnasal gastroscopy. Singapore Med J 2008;49:339-41.

15. Thanvi BR, Munshi SK, Vijayakumar N, et al. Acceptability of oesophagogastroduodenoscopy without intravenous sedation: patients' versus endoscopist's perception with special reference to older patients. Postgrad Med J 2003;79:650-1.

16. Kadayifci A, Atar M, Parlar S, et al. Transnasal endoscopy is preferred by transoral endoscopy experienced patients. $J$ Gastrointestin Liver Dis 2014;23:27-31.

17. Shaker R. Unsedated trans-nasal pharyngoesophagogastroduodenoscopy (T-EGD): technique. Gastrointest Endosc 1994;40:346-8.

18. Neuenschwander AU, Christensen M, Schulze S, et al. Less tachycardia during transnasal versus conventional gastroscopy. Dan Med J 2012;59.

19. Dumortier J, Josso C, Roman S, et al. Prospective evaluation of a new ultrathin one-plane bending videoendoscope for transnasal EGD: a comparative study on performance and tolerance. Gastrointest Endosc 2007;66:13-19.

20. Aviv JE, Takoudes TG, Ma G, et al. Office-based esophagoscopy: a preliminary report: SAGE publications, 2001. Available: http:// journals.sagepub.com/doi/abs/

21. Philpott H, Nandurkar S, Royce SG, et al. Ultrathin unsedated transnasal gastroscopy in monitoring eosinophilic esophagitis. $J$ Gastroenterol Hepatol 2016;31:590-4.

22. Campo R, Montserrat A, Brullet E. Transnasal gastroscopy compared to conventional gastroscopy: a randomized study of feasibility, safety, and tolerance. Endoscopy 1998;30:448-52.

23. Dumortier J, Ponchon T, Scoazec JY, et al. Prospective evaluation of transnasal esophagogastroduodenoscopy: feasibility and study on performance and tolerance. Gastrointest Endosc 1999;49:285-91.

24. Thota PN, Zuccaro G, Vargo JJ, et al. A randomized prospective trial comparing unsedated esophagoscopy via transnasal and transoral routes using a 4-mm video endoscope with conventional endoscopy with sedation. Endoscopy 2005;37:559-65.

25. Trevisani L, Cifalà V, Sartori S, et al. Unsedated ultrathin upper endoscopy is better than conventional endoscopy in routine outpatient gastroenterology practice: a randomized trial. World $J$ Gastroenterol 2007;13:906-11.

26. Mori A, Ohashi N, Yoshida A, et al. Unsedated transnasal ultrathin esophagogastroduodenoscopy may provide better diagnostic 
performance in gastroesophageal reflux disease. Dis Esophagus 2011;24:92-8.

27. Cheung J, Bailey R, Veldhuyzen van Zanten S, et al. Early experience with unsedated ultrathin 4.9 MM transnasal gastroscopy: a pilot study. Can J Gastroenterol 2008;22:917-22.

28. Preiss $\mathrm{C}$, Charton JP, Schumacher B, et al. A randomized trial of unsedated transnasal small-caliber esophagogastroduodenoscopy (EGD) versus peroral small-caliber EGD versus conventional EGD. Endoscopy 2003;35:641-6.

29. Maffei M, Dumortier J, Dumonceau J-M. Self-training in unsedated transnasal EGD by endoscopists competent in standard peroral EGD: prospective assessment of the learning curve. Gastrointest Endosc 2008;67:410-8.

30. Tatsumi Y, Harada A, Matsumoto T, et al. Current status and evaluation of transnasal esophagogastroduodenoscopy. Dig Endosc 2009;21:141-6.

31. Bajaj JS, Shaker R. Another indication for transnasal, unsedated upper-Gl endoscopy. Gastrointest Endosc 2005;62:667-8.

32. Bampton PA, Reid DP, Johnson RD, et al. A comparison of transnasal and transoral oesophagogastroduodenoscopy. $J$ Gastroenterol Hepatol 1998;13:579-84.

33. Yagi J, Adachi K, Arima N, et al. A prospective randomized comparative study on the safety and tolerability of transnasal esophagogastroduodenoscopy. Endoscopy 2005;37:1226-31.

34. Cohen J. A power primer. Psychol Bull 1992;112:155-9.

35. Dumortier J, Napoleon B, Hedelius F, et al. Unsedated transnasal EGD in daily practice: results with 1100 consecutive patients. Gastrointest Endosc 2003;57:198-204.

36. Murata A, Akahoshi K, Sumida Y, et al. Prospective randomized trial of transnasal versus peroral endoscopy using an ultrathin videoendoscope in unsedated patients. J Gastroenterol Hepatol 2007;22:482-5.
37. Craig A, Hanlon J, Dent J, et al. A comparison of transnasal and transoral endoscopy with small-diameter endoscopes in unsedated patients. Gastrointest Endosc 1999;49:292-6.

38. Faulx AL, Catanzaro A, Zyzanski S, et al. Patient tolerance and acceptance of unsedated ultrathin esophagoscopy. Gastrointest Endosc 2002;55:620-3.

39. Dumonceau JM, Dumortier J, Deviere J, et al. Transnasal OGD: practice survey and impact of a live video retransmission. Dig Liver Dis 2008;40:776-83.

40. Atar M, Kadayifci A. Transnasal endoscopy: technical considerations, advantages and limitations. World J Gastrointest Endosc 2014;6:41-8.

41. Saeian K, Townsend WF, Rochling FA, et al. Unsedated transnasal EGD: an alternative approach to conventional esophagogastroduodenoscopy for documenting Helicobacter pylori eradication. Gastrointest Endosc 1999;49:297-301.

42. Saeian K, Staff DM, Vasilopoulos S, et al. Unsedated transnasal endoscopy accurately detects Barrett's metaplasia and dysplasia. Gastrointest Endosc 2002;56:472-8.

43. Vitale MA, Villotti G, D'Alba L, et al. Unsedated transnasal percutaneous endoscopic gastrostomy placement in selected patients. Endoscopy 2005;37:48-51.

44. Külling $D$, Bauerfeind $P$, Fried $M$. Transnasal versus transoral endoscopy for the placement of nasoenteral feeding tubes in critically ill patients. Gastrointest Endosc 2000;52:506-10.

45. Fang JC, Hilden K, Holubkov R, et al. Transnasal endoscopy vs. fluoroscopy for the placement of nasoenteric feeding tubes in critically ill patients. Gastrointest Endosc 2005;62:661-6.

46. Yuki M, Amano Y, Komazawa Y, et al. Unsedated transnasal smallcaliber esophagogastroduodenoscopy in elderly and bedridden patients. World J Gastroenterol 2009;15:5586-91.

47. Shinozaki S, Miura Y, Ino Y, et al. An ultrathin endoscope with a 2.4$\mathrm{mm}$ working channel shortens the esophagogastroduodenoscopy time by shortening the suction time. Clin Endosc 2015;48:516-21. 